\title{
Morphology and dynamics of a premixed hydrogen-methane-air jet flame in hot vitiated turbulent crossflow
}

\section{Conference Paper}

Author(s):

Solana Pérez, Roberto (1); Miniero, Luigi (1); Shcherbanev, Serge (1); Bothien, Mirko R.; Noiray, Nicolas

Publication date:

2020

Permanent link:

https://doi.org/10.3929/ethz-b-000509037

Rights / license:

In Copyright - Non-Commercial Use Permitted

Originally published in:

4B, https://doi.org/10.1115/GT2020-16282

\section{Funding acknowledgement:}

831804 - Development of the Lean Azimuthal Flame as an Innovative aviation gas turbine low-NOX combustion concept (EC) 820091 - ThermoacOustic instabilities contRol in sequential Combustion cHambers (EC) 


\title{
Morphology and dynamics of a premixed hydrogen-methane-air jet flame in hot vitiated turbulent crossflow
}

\author{
Roberto Solana-Pérez ${ }^{\mathrm{a}}$, Luigi Miniero ${ }^{\mathrm{a}}$, Sergey Shcherbanev $^{\mathrm{a}}$, Mirko Bothien ${ }^{\mathrm{b}}$, Nicolas Noiray,a \\ ${ }^{a}$ CAPS Laboratory, Department of Mechanical and Process Engineering, ETH Zürich, Switzerland \\ ${ }^{b}$ Ansaldo Energia Switzerland Ltd, Baden 5401, Switzerland
}

\begin{abstract}
The effect of hydrogen enrichment of a premixed hydrogen-methane-air jet in hot vitiated crossflow was studied at atmospheric condition. The hot turbulent vitiated crossflow is generated by a symmetric array of $4 \times 4$ jet flames burning a lean mixture of natural gas and air in fully premixed condition at equivalence ratio $\varphi_{c f}=0.7$ and total thermal power of $50 \mathrm{~kW}$. This crossflow is then used to ignite the premixed perpendicular jet of hydrogen-methane-air at ambient temperature. Three jet parameters are varied to study the effect of hydrogen addition on the flame morphology and stabilization mechanism: the hydrogen mass fraction of the $\mathrm{H}_{2} / \mathrm{CH}_{4}$ fuel blend $(\xi=0-100 \%)$, the jet equivalence ratio $(\varphi=0.8-2.0)$ and the jet-to-crossflow momentum ratio $(J=3-12)$. High-speed hydroxyl $(\mathrm{OH})$ chemiluminescence is used to obtain the time-resolved imaging of the reactive jet and to compute its time averaged morphology. $\mathrm{OH}$ planar laser induced fluorescence (OH-PLIF) is used to acquire $\mathrm{OH}$ concentration fields at the jet center plane. The jet morphology is analyzed by considering its mean trajectory, extracted from the experimental data and fitted with empirical correlations available from the literature. New correlations are proposed for the flame length, width and center of gravity as function of the hydrogen content. It is shown that with increasing hydrogen fraction, the flame is shortened and more compact, and it stabilizes close to the jet root. Another finding of this work is the reattachment of the flame at the base of the windward jet shear layer when hydrogen fraction is increased. Robust flame anchoring is observed for $\mathrm{H}_{2}$ mass fractions of the $\mathrm{CH}_{4} / \mathrm{H}_{2}$ fuel blend that exceed 50\%. Moreover, it is shown using instantaneous OH-PLIF images that for these conditions of increasing hydrogen concentration, the windward shear layer features larger-scale coherent structures that govern the aerodynamics of the reactive premixed jet in turbulent vitiated crossflow.
\end{abstract}

Keywords: Hydrogen; Combustion; RJICF

\footnotetext{
* Corresponding author

Email address: noirayn@ethz.ch (Nicolas Noiray)
}

This is a pre-print version. Published in Proceedings of ASME Turbo Expo (2020) GT2020,

Vol. 4B: Combustion, fuels and emissions. DOI: 10.1115/GT2020-16282 


\section{INTRODUCTION}

The main drivers of modern gas turbine development are the high efficiency, the operational and fuel flexibility and the ultra-low emissions. Recent innovations to meet the objectives associated with these technology drivers are based on sequential and axially-staged combustion [1, 2]. These technologies offer higher operational and fuel flexibility compared to conventional single stage combustor concepts. They feature two combustion stages in series, working at constant pressure. The first stage is based on lean premixed turbulent combustion, while the second stage consists in fuel injection into the hot vitiated flow produced at the first stage, resulting in a reaction zone involving autoignition of the globally lean mixture. In this paper, we focus on a specific type of staged combustor which is based on a reactive premixed jet in hot vitiated crossflow (RJICF).

Most of the research on RJICF has been oriented towards experimental non-premixed configurations, injecting either pure gaseous fuel or oxidizer into a transverse flow $[3,4,5,6,7,8,9,10]$. In this type of configurations, the mixing process between fuel and oxidizer is dominated by the shear layer dynamics and it is critical for the ignition and stabilization of the flame. Micka and Driscoll [3] studied experimentally ethylene and hydrogen jet in hot crossflow. They identified 3 flame stabilization regions: an autoigniting region, a premixed flame propagating region and a turbulent non-premixed region. Steinberg et al. [4] made OH-PLIF measurements with $\mathrm{H}_{2} / \mathrm{N}_{2}$ fuel jets into hot crossflow. For each case, they found 2 distinct flame branches: one flame stabilized at the leeward jet side close to the recirculation region, and one unsteadily lifted at the windward jet side. Sullivan et al. [6] found experimental ignition times and locations to be of similar order of magnitude as those computed with 0D reactor simulations. Lyra et al. [7] and Nair et al. [10] investigated the dynamics of the leeward and windward flame branches of a hydrogen-helium jet. Non-premixed flame structures were found to dominate the high heat-release regions after ignition and a strong interplay between flame stabilization location and jet shear layer aerodynamic stability. By means of PIV and OH-PLIF Yi et al. [9] investigated the coherent flow structures developing upstream of the windward flame and triggering its ignition.

Inhomogeneities in the jet flame caused by insufficient mixing between fuel and air in a nonpremixed RJICF can generate high temperature hot-spots, often associated to high-NOx emissions. For this reason, research has recently focused on premixed RJICF configurations [11, 12, 13, 14, $15,16,17,18,19]$. Schmitt et al. [11] studied premixed preheated jets of air-NG over wide range of momentum and equivalence ratios, showing that flame ignition always occuring near the jet root in their configuration. Kolb et al. [12] varied crossflow and jet temperatures using same experimental setup as Schmitt et al. [11]. They showed that the jet flame liftoff is affected by the extent of mixture stratification at the jet windward side and they included the effect of both autoignition and propagation for its prediction. Wagner et al. [13, 14, 15] investigated experimentally an ethylene-air jet in hot crossflow using simultaneous PIV, OH and $\mathrm{CH}_{2} \mathrm{O}$ PLIF. They identified an unsteady lifted flame at the jet windward side and demonstrated that measured flame speeds are not consistent with premixed flame propagating speeds.

This is a pre-print version. Published in Proceedings of ASME Turbo Expo (2020) GT2020, Vol. 4B: Combustion, fuels and emissions. DOI: 10.1115/GT2020-16282 


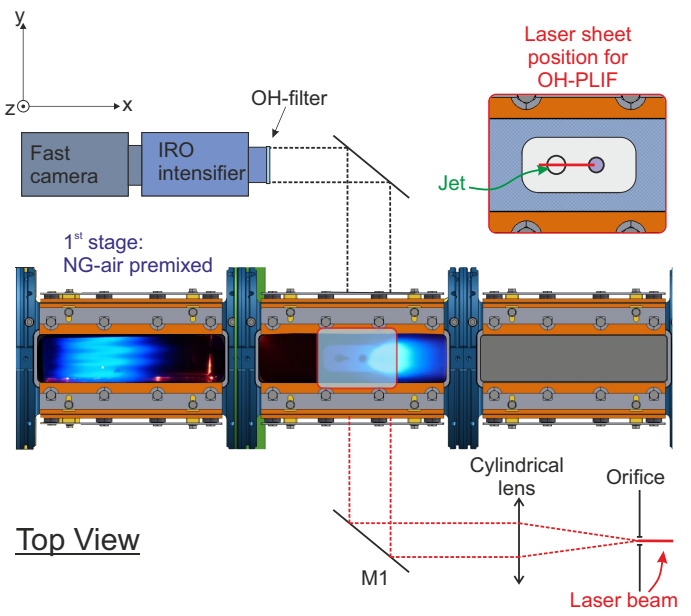

a)

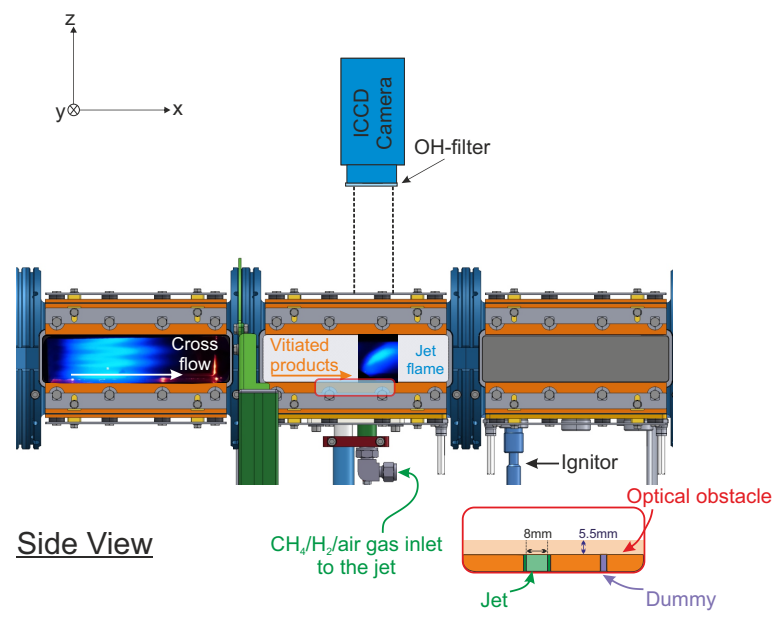

b)

Figure 1: Axially staged combustor. The first stage is composed of a $4 \times 4$ array of turbulent fully-premixed jet flames and the second stage is a jet flame in vitiated crossflow. a) Top view showing the fast camera and the intensifier used for high speed chemiluminescence imaging and the position of the laser sheet for oh-plif. b) Side view showing the premixed jet location and the iccd camera used for plif signal acquisition. The box in b) highlights that the frames of the quartz window act as an optical obstacle that prevents to see the entire dimension of the channel.

One of the possible solutions for $\mathrm{CO}_{2}$ emission reduction in future gas turbine technologies is the addition of hydrogen to premixed fuel-air mixture [20, 21]. However, adding $\mathrm{H}_{2}$ has substantial effects on flame stabilization, on blowoff limits and on NOx emissions, which motivated several academic work, especially in RJICF configuration. It was shown by Mendez et al. [22] on an example of co-flow configuration that even at low fraction of hydrogen additives in the fuel $(\sim 5 \%)$ increases the flame stabilization significantly. The presence of hydrogen also changes considerably the flame morphology compared to natural gas-air [22] and methane-air flames [23]. These changes include a substantial upstream shift of the stabilization region and the reduction or suppression of autoignition kernels. Karbasi et al. [20] investigated the change in the blowoff limits induced by the addition of hydrogen to methane in co-flowing stream. Di et al. [24] also shown that the flame vortex interaction increases with increasing hydrogen fraction in the fuel.

Jet morphology and trajectory are also of high interest for gas turbine applications. The jet flame should not be located close to the combustor walls for durability reasons and at the same time, the jet shape should give rise to homogeneous vertical distributions of temperature values to avoid strong gradients at the inlet of the turbine.

This paper focuses on the effects of gradual hydrogen addition on the stabilization and morphology of turbulent premixed jet in crossflow. The flame structure modifications caused by the increase of the hydrogen mass fraction in the fuel composition of the premixed jet and its effect on flame morphology and $\mathrm{OH}$ radicals distribution are analyzed by means of fast $\mathrm{OH}$ chemiluminescence and OH-PLIF imaging techniques.

This is a pre-print version. Published in Proceedings of ASME Turbo Expo (2020) GT2020, Vol. 4B: Combustion, fuels and emissions. DOI: 10.1115/GT2020-16282 


\section{SETUP AND METHODOLOGY}

The laboratory combustor, the operating conditions and the diagnostic techniques used in this work are presented in the following sub-sections.

\subsection{Experimental facility}

The experiments are conducted with a modular combustion test rig operated at atmospheric pressure, with a $62 \times 62 \mathrm{~mm}^{2}$ square cross section, composed of modules of $250 \mathrm{~mm}$ length connected by flanges. The combustor features a first and a second stage. Turbulent fully-premixed lean combustion of natural gas and air occurs in the first stage, where an array of $4 \times 4$ turbulent jet flames are anchored on a matrix burner. The second stage is based on a reactive jet in the hot vitiated crossflow from the first stage. The jet is composed by a premixed mixture of air, methane and hydrogen with different blending ratios. The first module downstream of the flame is equipped with 4 quartz windows for optical access. The jet is located $355 \mathrm{~mm}$ downstream of the oulet of the first stage burner, and originates from an injection pipe located in one of the walls of the second module of the combustion chamber. All the other walls of this module are quartz windows in order to perform optical diagnostics: high-speed chemiluminescence and $\mathrm{OH}$ planar laser induced fluorescence.

\subsection{Diagnostics}

The camera arrangement is shown in Fig. 1. Camera 1 is a LaVision highspeed star X camera with IRO intensifier, used to acquire series of 2000 chemiluminescence images at $20 \mathrm{kHz}(0.1 \mathrm{~s}$ of acquisition time). A $105 \mathrm{~mm}, \mathrm{f} / 4.5 \mathrm{UV}$ CoastalOpt SLR lens combined with a $\mathrm{OH}$ filter centered around $307.5 \mathrm{~nm}$ and with $10 \mathrm{~nm}$ full-width at half-maximum (FWHM) were used to focalise the camera. Top and side view of the jet were respectively acquired by placing the injector on the side and bottom wall of the module. The arrangement shown in Fig. 1 is also used to perform OH-PLIF of the jet flame when the injector is mounted on the side wall (not as depicted in Fig. 1). The laser sheet is formed in the $\mathrm{x}-\mathrm{y}$ plane. The LIF signal is obtained by using a frequency doubled dye laser (Quantel TDL 90 pumped with YG981, $20 \mathrm{~mJ}$ per pulse, $0.08 \mathrm{~cm}^{-1}$ FWHM) tuned to the $\mathrm{Q}_{1}(8)$ transition of the $\mathrm{OH}(\mathrm{A}-\mathrm{X})\left(\nu^{\prime}=1, \nu^{\prime \prime}=0\right)$ band near $283.55 \mathrm{~nm}$. A combination of cylindrical lenses ( $\mathrm{f}=-25 \mathrm{~mm}, \mathrm{f}=400 \mathrm{~mm}$ ) is used to form a collimated light sheet from the laser beam. 100 images at $10 \mathrm{~Hz}$ (10s of acquisition time) of the OH-fluorescence emissions on the horizontally oriented sheet are captured from above with the ICCD camera (PCO Dicam Pro), equipped with a Cerco, $100 \mathrm{~mm} \mathrm{f} / 2.8 \mathrm{UV}$ lens and a Chroma, T > $70 \%$ at $310 \mathrm{~nm}$, FWHM $10 \mathrm{~nm}$ bandpass interference filter. The gate of the ICCD camera is $200 \mathrm{~ns}$. The OH-PLIF signals had a spatial resolution of $120 \mu \mathrm{m}$.

\subsection{Test conditions}

The analysed test conditions were chosen in order to study the effect of the hydrogen blending on the morphology of a premixed jet flame in vitiated crossflow. The first stage is composed of

This is a pre-print version. Published in Proceedings of ASME Turbo Expo (2020) GT2020,

Vol. 4B: Combustion, fuels and emissions. DOI: 10.1115/GT2020-16282 


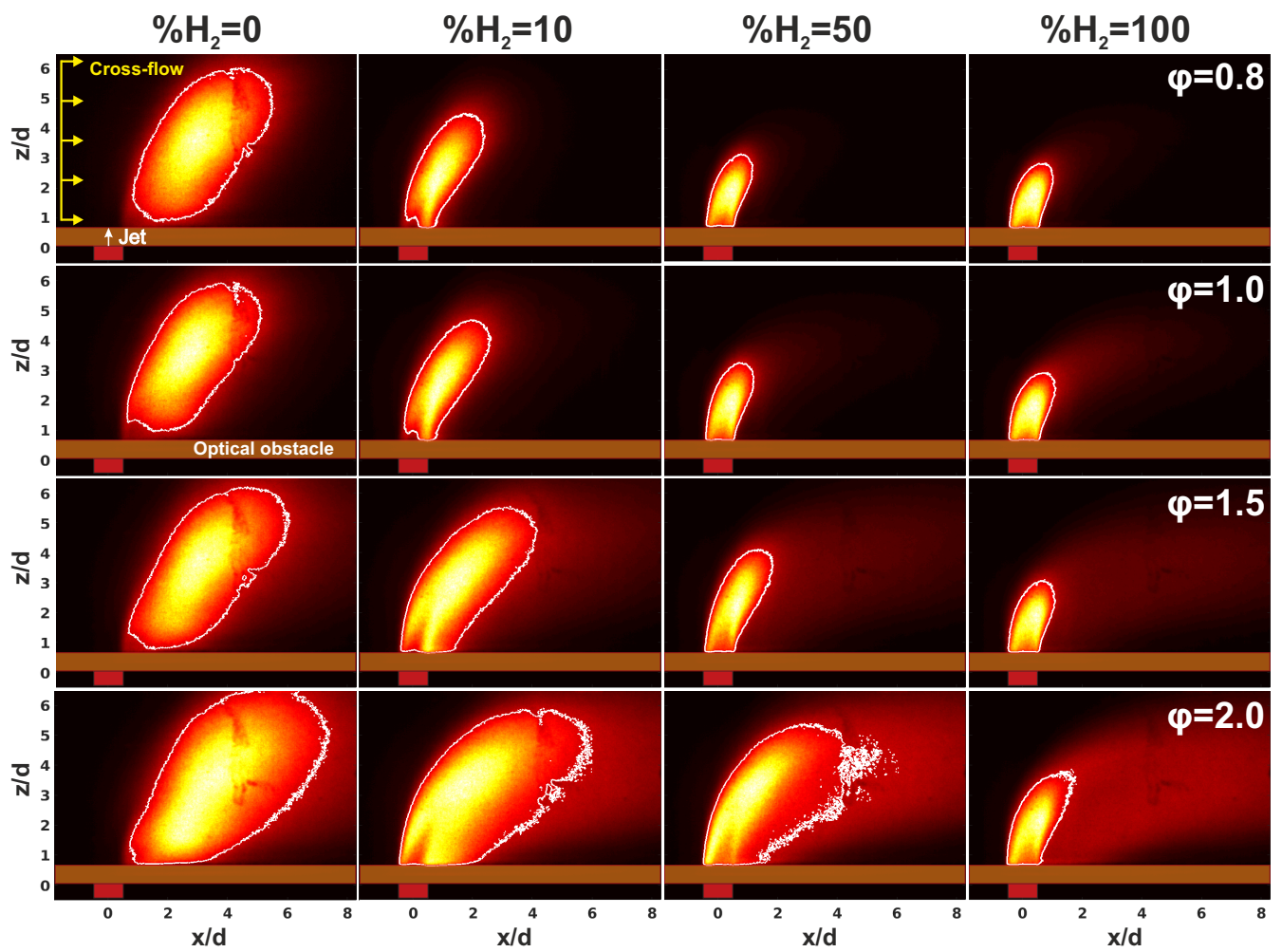

Figure 2: Averaged chemiluminescence of the reactive jet side-view, showing variation of hydrogen mass fraction in fuel mixture (horizontally: $\% \mathrm{H}_{2}=0,10,50,100$ ), and variation of jet mixture equivalence ratio (vertically: $\varphi=0.8,1.0,1.5,2.0)$ at constant $\mathrm{J}=8$. The fields are normalized by the maximum intensity at each condition. White iso-contour represents an intensity equal to $30 \%$ of the maximum. Jet pipe location and optical obstacle are depicted at the bottom of each subplot.

16 turbulent fully premixed natural-gas-air flames. Equivalence ratio and thermal power are kept constant at $\varphi_{f s}=0.7$ and $50 \mathrm{~kW}$, resulting in a crossflow temperature of $T_{c f}=1750 \pm 50 \mathrm{~K}$, which was measured with OH-PLIF thermometry [25]. The selected first-stage conditions results in $34 \mathrm{~m} / \mathrm{s}$ and $25.5 \mathrm{~g} / \mathrm{s}$ of crossflow velocity and mass flow.

Subsequently, the momentum ratio and the equivalence ratio of the premixed jet are varied independently in order to investigate the individual effects of these two parameters on the morphology of the flame. In the first data set, the momentum ratio $J=\left(\rho_{j} U_{j}^{2}\right) /\left(\rho_{c f} U_{c f}^{2}\right)$ is set to $3,5,8$ and 12 at a constant equivalence ratio $\varphi=1.5$. The second set of data corresponds to a constant momentum ratio $J=8$ and a variation of the equivalence ratio, with $\varphi$ successively set to $0.8,1$, 1.5 and 2.

This is a pre-print version. Published in Proceedings of ASME Turbo Expo (2020) GT2020, Vol. 4B: Combustion, fuels and emissions. DOI: 10.1115/GT2020-16282 


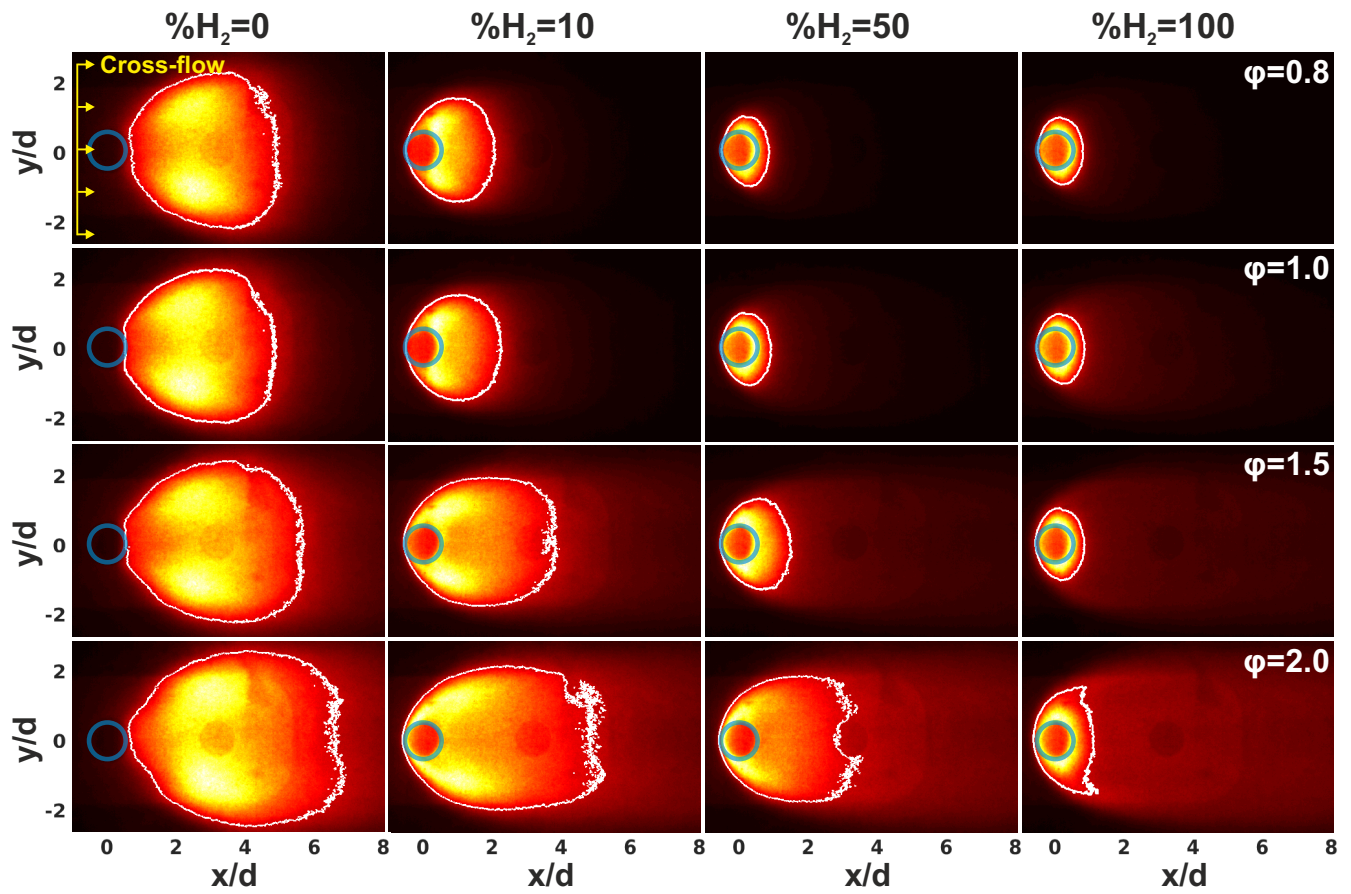

Figure 3: Averaged chemiluminescence fields of normalized intensity at jet top-field-of-view, showing variation of hydrogen fraction in fuel mixture (horizontally: $\% \mathrm{H}_{2}=0,10,50,100$ ), and variation of jet mixture equivalence ratio (vertically: $\varphi=0.8,1.0,1.5,2.0$ ) at constant $\mathrm{J}=8$. White iso-contour represents an intensity equal to $30 \%$ of the maximum. Jet exit location is depicted in each subplot as a blue circle.

\section{RESULTS AND DISCUSSION}

This section presents the results obtained from time-resolved $\mathrm{OH}^{*}$ chemiluminescence and $\mathrm{OH}$ planar laser induced fluorescence. Here, we study the variations of hydrogen fraction, jet equivalence ratio and jet-to-crossflow momentum ratio, and the effect that these variations have on the jet flame morphology and its dynamics.

\subsection{Jet flame morphology}

The jet flame morphology is studied from the time-averaged $\mathrm{OH}^{*}$ chemiluminescence intensity. The averaged fields were computed from a total of 2000 instantaneous images taken at $20 \mathrm{kHz}$ during a measuring time of $100 \mathrm{~ms}$. Figure 2 and 3 show respectively the side and top fields-ofview $(\mathrm{FoV})$ of the jet for varying hydrogen fractions (horizontally: $\left.\% \mathrm{H}_{2}=0,10,50,100\right)$ and jet equivalence ratios (vertically: $\varphi=0.8,1.0,1.5,2.0$ ). Each averaged intensity field spans from 0 to 1 , as they are normalized by the maximum value of each case. Jet exit location is depicted for clarity together with the hardware-related optical obstacle present in the side FoV of Fig. 2. The white isocontours correspond to $30 \%$ of the maximum chemiluminescence intensity of each case.

The images in Fig. 2 and 3 show for pure $\mathrm{CH}_{4}$ fuel (left column) that the windward side of the jet does not ignite for the current test conditions. Independently of the jet equivalence ratio, the

This is a pre-print version. Published in Proceedings of ASME Turbo Expo (2020) GT2020,

Vol. 4B: Combustion, fuels and emissions. DOI: 10.1115/GT2020-16282 
flame is lifted from jet root at the leeward side. At the current test conditions, the temperature values in the crossflow are not high enough to promote autoignition of the jet mixture in the windward side. Instead, ignition occurs at the leeward side and the flame stabilizes there, in the low velocity zone of the recirculation region. With the addition of hydrogen to the fuel mixture the reactivity of the jet increases significantly. This causes the autoignition times of the mixture to drop and promotes ignition of the windward side, moving the jet flame stabilization point closer to the jet root location. This can be observed by looking at the $30 \%$ white iso-contours. For low hydrogen fractions $(\sim 10 \%)$ one can observe decreasing lift-off height of the $30 \%$ white iso-contours for richer mixtures at the windward side, whereas at high fractions of hydrogen this iso-contour falls inside the optical obstacle for all equivalence ratios analysed. This suggests the existence of a threshold value of hydrogen fraction under which the windward flame stabilization location may vary with the jet mixture stoichiometry. Once this threshold is exceeded, the flame remains attached to the jet exit.

Regarding reaction zone morphology, the jet flame length, width and curvature decrease for increasing share of hydrogen, and to increase them for richer mixtures. A comparison between the lean (top row) and rich (bottom row) cases in Fig. 2 and 3, shows the effects of hydrogen to be more pronounced for leaner mixtures, i.e. leaner mixtures are more sensitive to hydrogen addition. This monotonic trend is quantitatively analysed in Fig. 4, where the flame geometry is fully characterized by four attributes: centerline, center of gravity (CoG), jet flame length $(\mathrm{L})$ and jet flame width (W), see Fig. 4f.

The center of gravity position is computed with respect to the origin and in terms of light intensity of the jet region enclosed in the $30 \%$ white iso-contour. Note that the origin is defined at the center of the jet pipe exit. The jet width is given by the distance between windward and leeward sides of the iso-contour in the normal direction to the jet centerline through the CoG. The jet length is calculated as the distance between the origin and the intersection of the centerline with the iso-contour. These 3 parameters are respectively plotted as function of $\% \mathrm{H}_{2}$ in Fig. $4 \mathrm{a}$, 4b, 4c for all the cases tested. Note that these jet geometric properties depend on the choice of contour edges. The plots show the monotonically decreasing trend of the jet flame parameters for increasing hydrogen fraction. Also, one can observe a greater sensitivity to hydrogen addition for equivalence ratio variations (blue curves) than for momentum ratio variations (red curves), especially when the jet mixture goes from lean to rich. The reason for this behavior is related to the dominant local combustion modes. For lean mixture combustion, the reaction is limited by the fuel availability, and the reaction takes places with fresh reactants coming from the jet. This creates a premixed type of flame dominated by the chemical properties of the mixture. A change of fuel will highly influence these chemical properties hence, influencing the combustion dynamics and flame characteristics. On the other hand, under rich conditions there is fuel excess from the jet that will react with the oxygen coming from the hot products of the lean-burned first stage. This means that this reaction will be highly dominated by diffusive effects, i.e. the mixing rates between jet and crossflow that allows this excess of fuel to react. In this case, a change of the

This is a pre-print version. Published in Proceedings of ASME Turbo Expo (2020) GT2020,

Vol. 4B: Combustion, fuels and emissions. DOI: 10.1115/GT2020-16282 

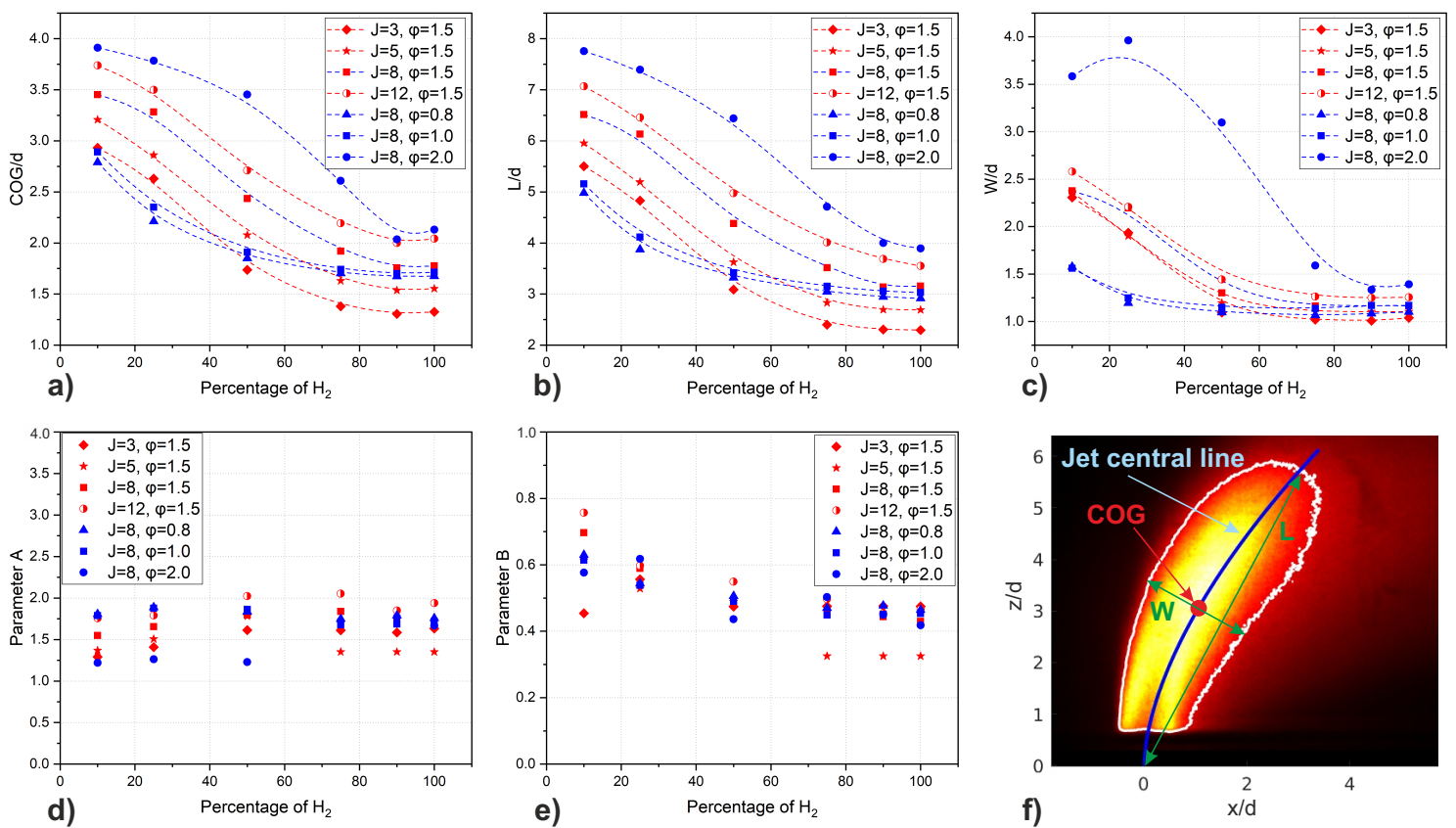

Figure 4: Dependence on hydrogen fraction on jet center of gravity position (a), jet length (b), jet width at center of gravity (c), and coefficients A (d) and B (e) from Eq. 1 [26], for all tested cases. Plot (f) features a jet averaged chemiluminescence intensity field showing the flame centerline, center of gravity, length and jet width.

fuel properties does not have such a strong impact, since diffusive effects dominate over chemical effects.

\subsection{Flame shape parametric characterization}

The jet centerline trajectory is determined from the chemiluminescence average intensity images, see Fig. 4f. It is computed as the midpoint between windward and leeward sides of the $30 \%$ white iso-contour in the normal direction to the jet centerline (as opposed to the vertical or horizontal directions). This results in $\mathrm{OH}^{*}$ chemiluminescence region. Consequently, it is rather independent of the choice of jet iso-contour edges. The jet centerline was extracted from all tested cases, and a curve fitting was performed to approximate the results obtained to the empirical correlation for jet trajectory given by Pratte and Baines [26] :

$$
\frac{y}{d \sqrt{J}}=A\left(\frac{x}{d \sqrt{J}}\right)^{B},
$$

where $\mathrm{y}$ is the vertical distance to the wall, $\mathrm{x}$ is the distance in the crossflow direction downstream of the injector and d is the jet diameter. $A$ and $B$ are coefficients that depend on parameters such as the velocity profile at jet exit, boundary layer thickness and the definition of the jet trajectory itself. The results for the parameters A and B obtained from the curve fitting can be observed in

This is a pre-print version. Published in Proceedings of ASME Turbo Expo (2020) GT2020,

Vol. 4B: Combustion, fuels and emissions. DOI: 10.1115/GT2020-16282 
Table 1: COEFFICIENTS FOR EQUATIONS 2 AND 3 OBTAINED FROM CURVE FITTING OF THE EXPERIMENTAL JET LENGTH VALUES FROM FIGURE $4 \mathrm{~b}$.

\begin{tabular}{cccc}
\hline & $\alpha$ & $\beta$ & $\gamma$ \\
\hline$L_{1}(\varphi, \xi)$ & 5.65 & 0.58 & -0.77 \\
$L_{2}(J, \xi)$ & 4.26 & 0.26 & -0.94 \\
\hline
\end{tabular}

Fig. $4 \mathrm{~d}$ and $4 \mathrm{e}$ respectively. As it can be observed, they are case dependent and do not follow a clear trend with respect to addition of hydrogen. However, they vary inside a rather short range of values. The ranges where they are most typically found for this specific test conditions are $1.2<A<2.1$ and $0.4<B<0.6$.

The correlation between the jet flame length and the main test parameters is analysed trough a parametric characterization of the experimental results in Fig. 4b. Two expressions are proposed to approximate the jet length as function of the main test parameters, i.e. jet equivalence ratio $(\varphi)$, jet-to-crossflow momentum ratio $(J)$ and hydrogen mass fraction in fuel $(\xi)$ :

$$
\begin{aligned}
& \mathrm{L}_{1}(\varphi, \xi)=\alpha_{1} \varphi^{\beta_{1}} \exp \left(\gamma_{1} \xi\right), \\
& \mathrm{L}_{2}(J, \xi)=\alpha_{2} J^{\beta_{2}} \exp \left(\gamma_{2} \xi\right) .
\end{aligned}
$$

Where the coefficients $\alpha_{i}, \beta_{i}$ and $\gamma_{i}$ are defined for this particular configuration and test conditions. Their values are listed in Table 1. The first expression, Eq. 2, is derived for constant momentum ratio $(J=8)$ and varying jet equivalence ratios $(\varphi=0.8,1.0,1.5,2.0)$, corresponding to the blue dashed lines in Fig. 4b. The second expression, Eq. 3, is derived for constant jet equivalence ratio $(\varphi=1.5)$ and varying momentum ratios $(J=3,5,8,12)$, corresponding to the red markers in Fig. 4b. The results of the empirical fitting and the comparison to the experimental data are shown in Fig. 5a for Eq. 2, and Fig. 5b for Eq. 3, showing that the decreasing monotonic trend of jet length for increasing fuel hydrogen fraction is well captured in all tested cases.

\subsection{Jet flame dynamics}

The instantaneous images from OH-PLIF are used to highlight features of the jet flame dynamics. The low image acquisition rate $(10 \mathrm{~Hz})$ does not allow capturing time-resolved flame dynamics. However, conclusions can be drawn from the instantaneous $\mathrm{OH}$ fields about the main features that characterise the jet flame dynamics for each test condition. Figure 6 summarizes the results of OH-PLIF images for the two sets of experiments, i.e. varying jet equivalence ratios $(\varphi=0.8,1.0,1.5,2.0)$ at constant momentum ratio $(J=8)$ in the left; and varying momentum ratios $(J=3,5,8,12)$ at constant jet equivalence ratio $(\varphi=1.5)$ in the right. The instantaneous images are normalized with the overall maximum value of all the images plotted in each figure, so that a proper comparison can be done between the different subplots.

This is a pre-print version. Published in Proceedings of ASME Turbo Expo (2020) GT2020, Vol. 4B: Combustion, fuels and emissions. DOI: 10.1115/GT2020-16282 

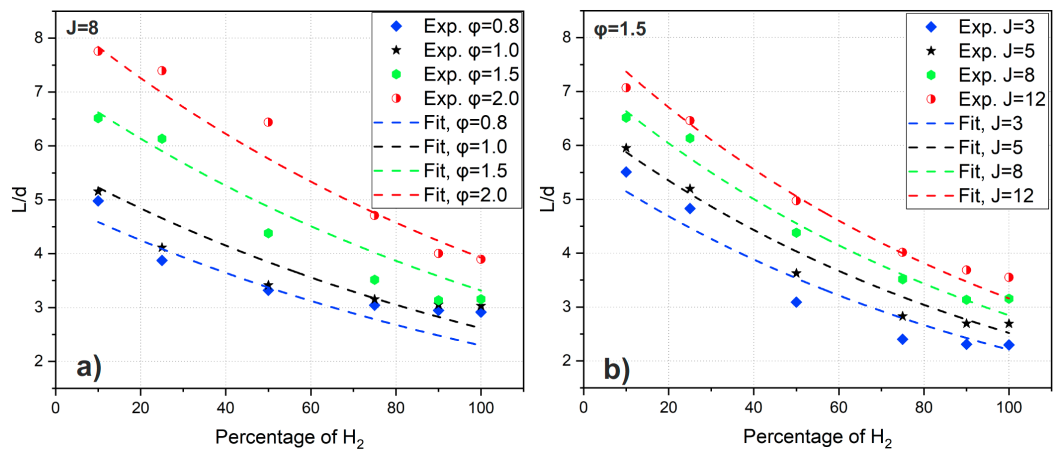

Figure 5: Comparison of experimental (markers) and analytical (dashed lines) jet lengths as function of hydrogen fraction for varying jet equivalence ratio (a) and momentum ration (b). Analytical lengths obtained from Eq. 2 and 3 respectively.

The absence of $\mathrm{OH}$ at the jet windward side for $\xi=0$ confirms the absence of windward flame, while robust windward flame anchoring is observed for $\xi \geq 50 \%$. The reactive flow under analysis is highly complex and many factors are at play which are not independent from each other. Nevertheless, for all combinations of $\varphi$ and $J$ tested, large scale coherent structures developed along the windward shear layer. Their size increase for increasing hydrogen fraction. In the cases of pure methane or small hydrogen fractions (left columns), the windward shear layers present a strongly wrinkled profile, typical of highly turbulent mixing layers. However, for increasing $\mathrm{H}_{2}$ fractions this strong wrinkling is reduced and the above-mentioned large-scale coherent structures govern the flow dynamics. Several considerations should be taken into account to understand this transition. Firstly, the modification of the jet mixture for a fixed $J$ keeps the product $\rho_{\text {jet }} u_{\text {jet }}^{2}$ constant, but it leads to increasing jet flow speeds $u_{j e t}$ and decreasing jet mass flow rates as the mixture density decreases due to the addition of hydrogen. We can express this change in terms of the local Reynolds number between two cases of methane enriched with low (case 1) and high (case 2) mass fractions of hydrogen. Considering $J$ constant, one has $\rho_{j e t, 1} u_{j e t, 1}^{2}=\rho_{j e t, 2} u_{j e t, 2}^{2}$ and with $R e=\rho_{j e t} u_{j e t} L / \mu$ being the jet Reynolds number, one can derive

$$
\frac{R e_{2}}{R e_{1}}=\frac{\mu_{1}}{\mu_{2}} \sqrt{\frac{\rho_{2}}{\rho_{1}}}<1,
$$

where the subscripts refer to cases 1 and 2 . In that expression, the ratio of density dominates over the ratio of viscosity when we compare pure hydrogen and pure methane (note that the relations are linear with mixture fraction of both mixture components). So increasing fractions of hydrogen decrease the jet Reynolds number, hence the turbulence level and the mixing-rate in the shear layer.

Secondly, the addition of hydrogen at constant $J$ increases the power output of the jet. The associated increased heat release rate causes expansion of the jet and higher temperatures in the flow, which affects the development of the coherent structures and the mixing rate. From this

This is a pre-print version. Published in Proceedings of ASME Turbo Expo (2020) GT2020,

Vol. 4B: Combustion, fuels and emissions. DOI: 10.1115/GT2020-16282 

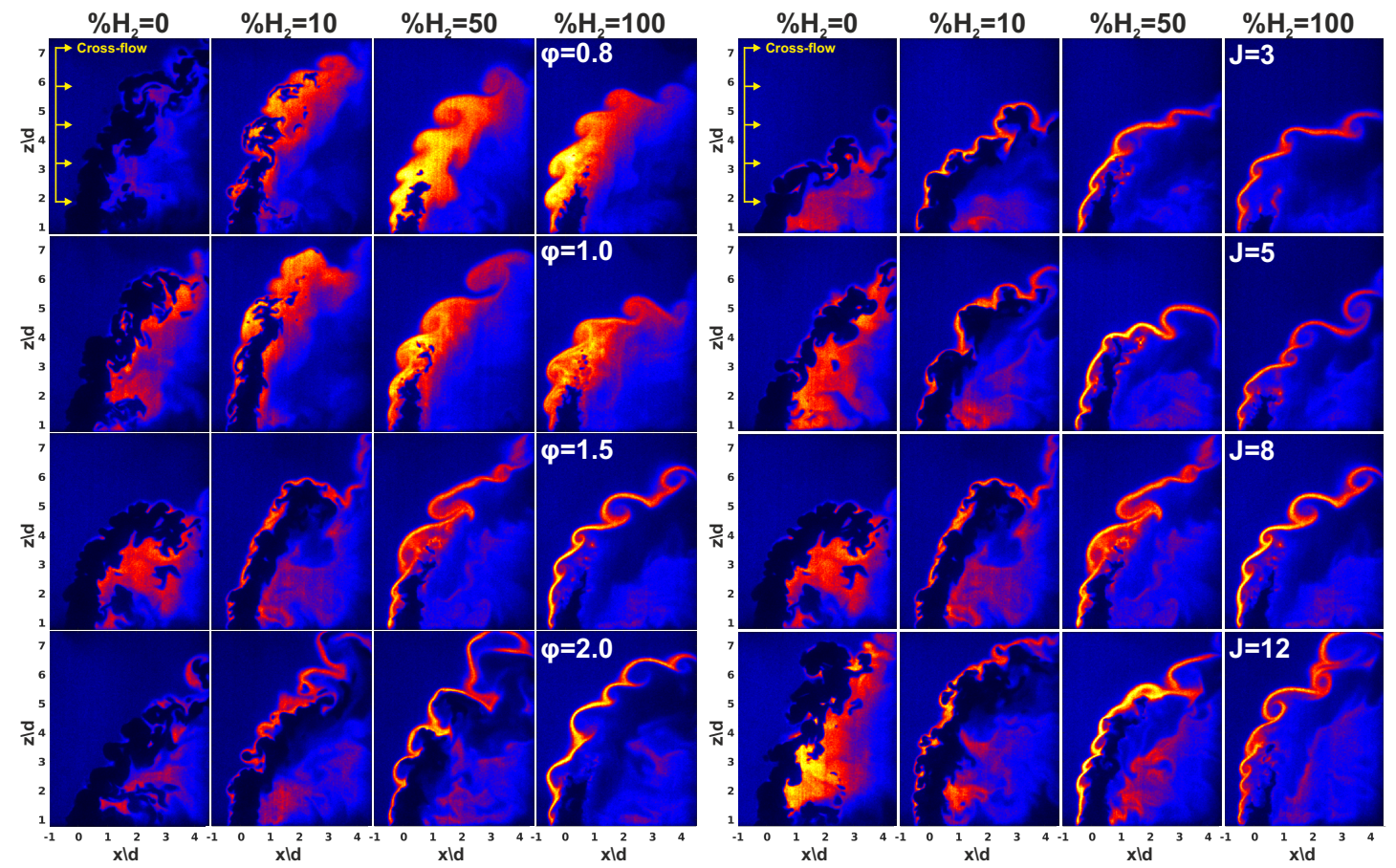

Figure 6: Instantaneous OH-PLIF signal for: (left) different jet equivalence ratios $(\varphi=0.8,1.0,1.5,2.0$, constant $\mathrm{J}=$ 8 ), and (right) different momentum ratios $(J=3,5,8,12$, constant $\varphi=1.5)$, at various hydrogen mass percentages in fuel $\left(\% \mathrm{H}_{2}=0,10,50,100\right)$.

perspective, a jet with fixed composition in which the power output is increased would become larger, with higher strain rates in the shear layer and higher vortex stretching around the jet body. This can lead to flame quenching and prevent ignition in those regions. However, in the current case, the jet flame does not grow and actually becomes smaller for increasing jet power output. This can be explained by the fact that hydrogen addition increases the fuel blend reactivity.

\section{CONCLUSIONS}

This paper presents experimental results of a premixed hydrogen-methane-air jet burning in a hot vitiated turbulent crossflow at atmospheric pressure. The aim of the study is to analyse the effect that hydrogen addition to the premixed jet mixture has over the flow and combustion dynamics. Three test parameters are varied: jet-to-crossflow momentum ratio $J=3,5,8,12$, jet equivalence ratio $\varphi=0.8,1.0,1.5,2.0$ and hydrogen mass fraction in fuel $\xi=0,0.1,0.25,0.5,0.75,0.9,1$ (or in volume fraction $\chi=0,0.47,0.73,0.89,0.96,0.99,1)$. The averaged fields from high speed $\mathrm{OH}^{*}$ chemiluminescence show an overall reduction of jet length, width and curvature for increasing hydrogen fraction in all the combinations of $\varphi$ and $J$ tested. Furthermore, it is observed that sensitivity of the jet morphology to hydrogen addition is higher for richer mixtures. The time-averaged

This is a pre-print version. Published in Proceedings of ASME Turbo Expo (2020) GT2020,

Vol. 4B: Combustion, fuels and emissions. DOI: 10.1115/GT2020-16282 
jet trajectories are fitted and compared to empirical correlations from the literature, showing good agreement. Furthermore, a parametric characterization of the jet length is done with the experimental results and an empirical correlation is proposed to estimate it as function of jet-to-crossflow momentum ratio and hydrogen mass fraction. Instantaneous OH-PLIF images of the symmetry plane of the jet are used to describe the aerodynamics of the jet. It is shown that in all cases tested the addition of hydrogen to the fuel mixture leads to the ignition of the windward shear layer and the development of large scale coherent structures. Furthermore, these images show the absence of $\mathrm{OH}$ production in the jet windward shear layer for $\% \mathrm{H}_{2}=0$, i.e. the absence of windward flame. At values of $\% \mathrm{H}_{2} \sim 50$ robust flame anchoring at jet exit occurs. Quantitative analysis of the thermo-chemical and aerodynamic mechanisms, which lead to the observed flame reattachment when hydrogen is added to the fuel blend, is subject to future work.

\section{Acknowledgment}

Financial supports of the Swiss Federal Office of Energy under the research project No. Sl/50178101 (ARCH), of the European Union under the H2020 Clean Sky 2 Joint Undertaking (JU) Research and Innovation Action No. 831804 (LEAFINNOX), and of the European Research Council under the Consolidator Grant No. 820091 (TORCH) are gratefully acknowledged. Clean Sky 2 JU receives support from the European Union's Horizon 2020 research and innovation programme and the Clean Sky 2 JU members other than the Union.
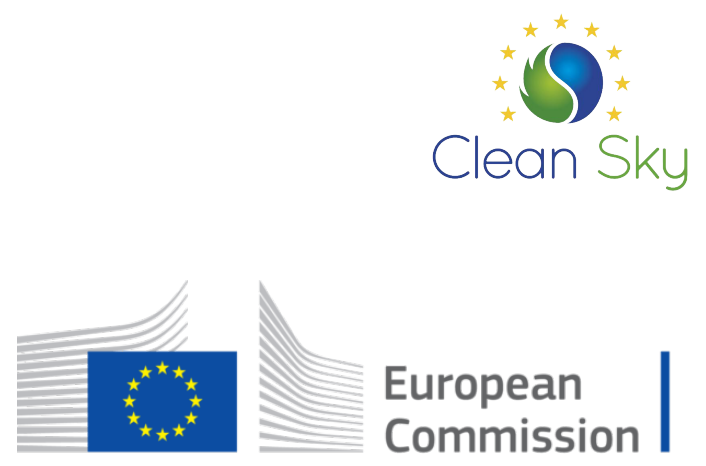

Horizon 2020

European Union funding

for Research \& Innovation

\section{References}

[1] Pennell, D. A., Bothien, M. R., Ciani, A., Granet, V., Singla, G., Thorpe, S., Wickstroem, A., Oumejjoud, K., and Yaquinto, M., 2017. "An introduction to the ansaldo gt36 constant pressure sequential combustor". In ASME Turbo Expo 2017: Turbomachinery Technical Conference and Exposition, American Society of Mechanical Engineers Digital Collection.

[2] Karim, H., Natarajan, J., Narra, V., Cai, J., Rao, S., Kegley, J., and Citeno, J., 2017. "Staged combustion system for improved emissions operability and flexibility for 7ha class heavy duty gas turbine engine". In ASME turbo expo 2017: turbomachinery technical conference and exposition, American Society of Mechanical Engineers Digital Collection.

This is a pre-print version. Published in Proceedings of ASME Turbo Expo (2020) GT2020,

Vol. 4B: Combustion, fuels and emissions. DOI: 10.1115/GT2020-16282 
[3] Micka, D. J., and Driscoll, J. F., 2012. "Stratified jet flames in a heated (1390 k) air cross-flow with autoignition". Combustion and Flame, 159(3), pp. 1205-1214.

[4] Steinberg, A. M., Sadanandan, R., Dem, C., Kutne, P., and Meier, W., 2013. "Structure and stabilization of hydrogen jet flames in cross-flows". Proceedings of the Combustion Institute, 34(1), pp. 1499-1507.

[5] Fleck, J. M., Griebel, P., Steinberg, A. M., Arndt, C. M., Naumann, C., and Aigner, M., 2013. "Autoignition of hydrogen/nitrogen jets in vitiated air crossflows at different pressures". Proceedings of the Combustion Institute, 34(2), pp. 3185-3192.

[6] Sullivan, R., Wilde, B., Noble, D. R., Seitzman, J. M., and Lieuwen, T. C., 2014. "Timeaveraged characteristics of a reacting fuel jet in vitiated cross-flow". Combustion and Flame, 161(7), pp. 1792-1803.

[7] Lyra, S., Wilde, B., Kolla, H., Seitzman, J. M., Lieuwen, T. C., and Chen, J. H., 2015. "Structure of hydrogen-rich transverse jets in a vitiated turbulent flow". Combustion and Flame, 162(4), pp. 1234-1248.

[8] Sidey, J., and Mastorakos, E., 2015. "Visualization of mild combustion from jets in cross-flow". Proceedings of the Combustion Institute, 35(3), pp. 3537-3545.

[9] Yi, T., Halls, B., Jiang, N., Felver, J., Sirignano, M., Emerson, B., Lieuwen, T., Gord, J., and Roy, S., 2019. "Autoignition-controlled flame initiation and flame stabilization in a reacting jet in crossflow". Proceedings of the Combustion Institute, 37(2), pp. 2109-2116.

[10] Nair, V., Wilde, B., Emerson, B., and Lieuwen, T., 2019. "Shear layer dynamics in a reacting jet in crossflow". Proceedings of the Combustion Institute, 37(4), pp. 5173-5180.

[11] Schmitt, D., Kolb, M., Weinzierl, J., Hirsch, C., and Sattelmayer, T., 2013. "Ignition and flame stabilization of a premixed jet in hot cross flow". In ASME Turbo Expo 2013: Turbine Technical Conference and Exposition, American Society of Mechanical Engineers Digital Collection.

[12] Kolb, M., Ahrens, D., Hirsch, C., and Sattelmayer, T., 2016. "A model for predicting the lift-off height of premixed jets in vitiated cross flow". Journal of Engineering for Gas Turbines and Power, 138(8), p. 081901.

[13] Wagner, J. A., Grib, S. W., Renfro, M. W., and Cetegen, B. M., 2015. "Flowfield measurements and flame stabilization of a premixed reacting jet in vitiated crossflow". Combustion and Flame, 162(10), pp. 3711-3727.

[14] Wagner, J., Renfro, M., and Cetegen, B., 2017. "Premixed jet flame behavior in a hot vitiated crossflow of lean combustion products". Combustion and Flame, 176, pp. 521-533.

[15] Wagner, J. A., Grib, S. W., Dayton, J. W., Renfro, M. W., and Cetegen, B. M., 2017. "Flame stabilization analysis of a premixed reacting jet in vitiated crossflow". Proceedings of the Combustion Institute, 36(3), pp. 3763-3771.

[16] Panda, P. P., Busari, O., Lucht, R. P., and Laster, W. R., 2017. "Effect of the nature of vitiated crossflow on the flow-field of a transverse reacting jet". Experiments in Fluids, 58(2), p. 9.

[17] Dayton, J. W., Linevitch Jr, K., and Cetegen, B. M., 2019. "Ignition and flame stabilization of a premixed reacting jet in vitiated crossflow". Proceedings of the Combustion Institute, 37(2), pp. 2417-2424.

[18] Sirignano, M. D., Nair, V., Emerson, B., Seitzman, J., and Lieuwen, T. C., 2019. "Nitrogen oxide emissions from rich premixed reacting jets in a vitiated crossflow". Proceedings of the Combustion Institute, 37(4), pp. 5393-5400.

[19] Panda, P. P., Busari, O., Roa, M., and Lucht, R. P., 2019. "Flame stabilization mechanism in reacting jets in swirling vitiated crossflow". Combustion and Flame, 207, pp. 302-313.

[20] Karbasi, M., and Wierzba, I., 1998. "The effects of hydrogen addition on the stability limits of

This is a pre-print version. Published in Proceedings of ASME Turbo Expo (2020) GT2020,

Vol. 4B: Combustion, fuels and emissions. DOI: 10.1115/GT2020-16282 
methane jet diffusion flames". International Journal of Hydrogen Energy, 23(2), pp. 123-129.

[21] Cho, E.-S., and Chung, S. H., 2009. "Improvement of flame stability and no x reduction in hydrogen-added ultra lean premixed combustion". Journal of Mechanical Science and Technology, 23(3), pp. 650-658.

[22] Mendez, L. A., Tummers, M., Van Veen, E., and Roekaerts, D., 2015. "Effect of hydrogen addition on the structure of natural-gas jet-in-hot-coflow flames". Proceedings of the Combustion Institute, 35(3), pp. 3557-3564.

[23] Emadi, M., Karkow, D., Salameh, T., Gohil, A., and Ratner, A., 2012. "Flame structure changes resulting from hydrogen-enrichment and pressurization for low-swirl premixed methane-air flames". international journal of hydrogen energy, 37(13), pp. 10397-10404.

[24] Di Sarli, V., Di Benedetto, A., Long, E. J., and Hargrave, G. K., 2012. "Time-resolved particle image velocimetry of dynamic interactions between hydrogen-enriched methane/air premixed flames and toroidal vortex structures". international journal of hydrogen energy, $\mathbf{3 7}(21)$, pp. 16201-16213.

[25] Heinze, J., Meier, U., Behrendt, T., Willert, C., Geigle, K.-P., Lammel, O., and Lückerath, R., 2011. "Plif thermometry based on measurements of absolute concentrations of the oh radical". Zeitschrift für Physikalische Chemie, 225(11-12), pp. 1315-1341.

[26] Pratte, B. D., and Baines, W. D., 1967. "Profiles of the round turbulent jet in a cross flow". Journal of the Hydraulics Division, 93(6), pp. 53-64.

This is a pre-print version. Published in Proceedings of ASME Turbo Expo (2020) GT2020, Vol. 4B: Combustion, fuels and emissions. DOI: 10.1115/GT2020-16282 